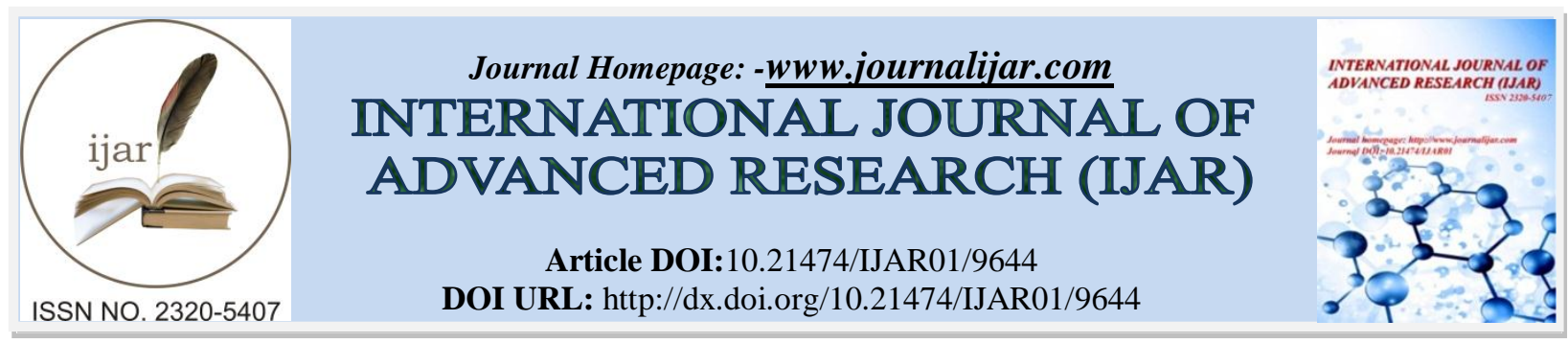

RESEARCH ARTICLE

\title{
DIAGNOSTIC IMPORTANCE OF MATRIX METALLOPROTEINASE 2 AND 9 AS ADDITIONAL BIOMARKERS IN THE SERA OF BREAST CANCER PATIENTS.
}

Solanki Sulabhsinh ${ }^{1}$ and Shah Menka ${ }^{2}$.

1. Department of Microbiology, Shree M. \& N. Virani Science College, YogidhamGurukul, Kalawad Road, Rajkot-360005, Gujarat, India.

2. Department of Pathology, Pramukh Swami Medical College, Karamsad-388325, Gujarat, India.

\section{Manuscript Info}

Manuscript History

Received: 04 July 2019

Final Accepted: 06 August 2019

Published: September 2019

Key words:-

Biomarker, Breast cancer, MMP-2, MMP-9.

\section{Abstract}

Introduction: Tumor invasion and metastasis are the critical steps in breast cancer, leading to detrimental conditions. Matrix metalloproteinase (MMP) 2 and 9 play significant role in progression of breast cancer by degrading type IV collagen. Therefore, the main purpose of the present study was to estimate the concentration of MMP-2 and MMP-9 in the sera of breast cancer patients using zymography and correlate data with existing clinical parameters.

Materials \& Methods: Sera was collected from 70 breast cancer patients before surgery or who underwent surgery and 50 healthy controls and the activity levels of MMP-2 and MMP-9 were quantified by performing gelatin zymography. Statistical analysis was carried out by using SPSS statistical software (version 20) and Minitab (version 16).

Results: The results show that average levels of both MMP-2 and MMP-9 were significantly higher in sera of breast tumor patients as compared to sera of benign breast disease and control group $(p<0.001)$. Additionally, statistical analysis revealed significant direct correlations between levels of both MMPs with different clinical parameters including breast tumor stage, size and tumor grade. Moreover, it was also found that high serum levels of MMP-2 and MMP-9 were associated with lymph node metastasis.

Conclusion: Our findings suggest the importance of the detection of serum MMP-2 and MMP-9 as additional biomarkers for the diagnosis of breast cancer and significant clinical use of these enzymes in malignant tumor growth, invasion and metastasis.

Copy Right, IJAR, 2019,. All rights

reserved.

\section{Introduction:-}

Breast cancer is the most commonly occurring female cancer worldwide. Every year $23 \%$ of new cases occur of breast cancer globally of which $13.7 \%$ cases results in to the death. In India, breast cancer is one of the most common cancer and frequently found amongst women in metropolitan cities. Recently, breast cancer which has been

Corresponding Author:-Solanki Sulabhsinh.

Address:-Department of Microbiology, Shree M. \& N. Virani Science College, Yogidham Gurukul, 167 
on a steady rise has over taken cervical cancer as the most common and deadly killer disease of the new era with estimated 1.5 lakh (over 10 per cent of all cancers) new cases during 2016 and the figure is likely to reach nearly 17.3 lakh new cases in 2020. The 1 in 28 women in India is likely to develop breast cancer during her lifetime . $^{1,2}$.

In general, cancer develops due to imbalance in homeostatic regulation at intra- and intercellular level which results in malignant transformation. Tumor cell invasion and metastasis requires precise coordination of adherence to extracellular matrix (ECM) and controlled degradation of its components resulting in metastasis, a prominent characteristic of cancer ${ }^{3}$. The metastatic process involves intravasation and extravasation of tumor cells, followed by reimplantation of tumor cells, formation of new tumor stroma and neoanginogenesis, to develop a secondary tumor at a distant side ${ }^{4}$. These steps in the spreading of malignant tumors are primarily influenced by the activity of proteinases, which can either degrade or alter the protein components of the ECM. These proteinases facilitate the detachment of tumor cells, their crossing of tissue boundaries and invasion into adjacent tissue compartments by the degradation of ECM and components. To the date, at least four classes of proteinases are known: serine proteinases, aspartatic proteinases, cystein proteinases and matrix metalloproteinases (MMPs) ${ }^{5,6}$. Recently, MMPs have attracted the interest of researcher as they play key role in cancer invasion and metastasis.

MMPs are a family of highly homologous, zinc and calcium dependent extracellular enzymes and are structurally and functionally related endopeptidases. Till date, more than 25 members of the MMP family are found in humans. MMPs, based on substrate specificity, protein domain structure, sequence homology and ability or inability to be secreted, are classified into 6 sub classes viz. collagenases, gelatinases, stromelysins, matrilysins, membrane-type MMPs and others ${ }^{5-9}$.Amongst these, two gelatinases, i.e. MMP-2 (gelatinase A) and MMP-9 (gelatinase B) are of particular interest as they play important role in early cancer development and progression. MMP-2 and MMP-9 degrades the type IV collagen, a major component of the basement membrane and constitutes an important barrier to tumour cell invasion. MMPs, in biological systems or fluids, occur either as inactive proenzymes, active enzymes and inactive enzymes bound by various inhibitors ${ }^{10}$. More recent evidence suggests that MMP-2 and MMP-9 may also be involved in breast cancer initiation and growth through complex interactions with the main oncogenes and tumour-suppressor genes involved in the early stage of tumorigenesis. Therefore, several authors have proposed MMP-2 and MMP-9 as useful prognostic markers. They may be useful as markers for early breast cancer detection, disease classification or treatment monitoring. In the present research, the activity levels of MMP-2 and MMP-9 were detected and quantified by using highly sensitive zymographic method to support their diagnostic value, then mean level of MMP-2 and MMP-9 was compared in between control group and malignant breast tumor and finally activity levels of serum forms of MMP-2 and MMP-9 were correlated with the current clinical parameters by performing statistical analysis.

\section{Materials \& Methods:- Study Subject}

This observational case-control study included 45 female breast cancer patients and 25 female benign breast disease patients before surgery or who underwent surgery as the primary treatment at Surgical/Oncology department of Shree Krishna Hospital, Karamsad, during the period of June, 2012 to November, 2016. The control group consisted of 50 healthy aged matched women living in the same geographic area and relatives of breast cancer patients without any history of cancer, inflammation or any other major illness. Breast cancer patients who had undergone chemotherapy or radiation therapy before surgery and patients suffering from other breast diseases were also excluded. To asses possible correlations between serum levels of MMP-2 and MMP-9 and the stage of the disease, data on following clinical parameters were collected: Menopausal state, tumor stage (early and advanced), tumor size ( $\mathrm{T}$ factor), lymph node involvement ( $\mathrm{N}$ factor), histological grading, estrogen receptor (ER) levels, progesterone receptor (PR) levels and HER2/ neu status. This study was approved by the Institutional Human Research Ethics Committee. The study patients were informed about the objective of the study. An informed consent was taken from all patients and female of control group.

\section{Blood sample collection}

Venous blood sample, approx. 5-6 ml, was collected in plastic tubes without coagulation accelerators, to prevent the release of gelatinases during platelet activation from all patients and controls. The blood samples were centrifuged at $2000 \mathrm{rpm}$ for 10 minutes and the sera were separated according to the ethical standards. The protein concentration, from each sample, was determined using Bradford's method; while the remaining serum samples were preserved at $-80{ }^{\circ} \mathrm{C}$ in small aliquots. 


\section{Preparation of euglobulins}

Euglobulin fractions were prepared as described by Ranuncoloet al. ${ }^{11}$ with minor modifications as follows: $0.1 \mathrm{ml}$ serum sample was mixed with $0.9 \mathrm{ml}$ chilled deionised distilled water and acidified with $40 \mu 1$ of $1 \%$ acetic acid $(\mathrm{pH}$ 5.5) and incubated at $0^{\circ} \mathrm{C}$ for 1 hour. Then, it was centrifuged at 5,000 rpm for 10 min. Euglobulin fraction (as pellet) was collected and dissolved in $1 \mathrm{~mL}$ phosphate-buffered saline (PBS) solution (pH 7.4), so that the final dilution was 1:10.

\section{Method (Gelatin Zymography)}

A substrate level gelatin zymography was performed from freshly prepared euglobulin fractions of control group and malignant breast tumor patients. Briefly, the euglobulin fraction was mixed with sample buffer dye (50 mMTris$\mathrm{HCl}, 2 \% \mathrm{SDS}, 10 \%$ glycerol, $0.1 \%$ bromophenol blue) without reducing agent. The mixture was incubated at room temperature for 30 minutes, and then electrophoresed on $8 \%$ sodium dodecyl sulphate-polyacrylamide (SDSPAGE). Gels were copolymerised with heat denatured type A gelatine (0.1\%) (HiMedia) as enzyme substrate. For each sample, $40 \mu \mathrm{g}$ of total serum protein was loaded. Electrophoresis was carried out using the Mini protean tetra cell unit (e.g., apparatus from Bio-Rad Laboratories) at $100 \mathrm{~V}$ constant voltage, using $1 \times$ pre cooled electrophoresis running buffer at $4^{\circ} \mathrm{C}$ for $120 \mathrm{~min}$ or until the dye front reaches the bottom of the gel. After electrophoresis, gels were washed twice in renaturation buffer $(2.5 \%$ Triton $\mathrm{X}-100, \mathrm{pH} 7.5)$ for 30 minutes each time to remove SDS. Then the zymograms were incubated overnight in incubation buffer $\left(50 \mathrm{mMTris}-\mathrm{HCl}\right.$ buffer, $10 \mathrm{mM} \mathrm{CaCl}_{2}, 2 \%$

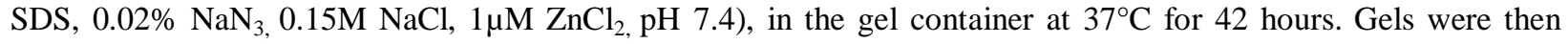
stained with Coomassie Brilliant Blue R-250, in 45\% methanol for a minimum 1 hour and destained with 30\% methanol and $10 \%$ acetic acid in distilled water, until the clear bands were revealed. Areas of enzymatic activity appeared as clear bands on a uniformly blue background.

\section{Quantification of enzymatic activity}

Following zymography, all the zymograms were quantified using the Bio-Rad gel documentation system (i.e. BioRad XR Plus, Hercules, California, Version 5.2.1). The relative proteinases activity was determined for each proteinase by multiplying the area of each lysed band by its optical density $\left(\mathrm{OD}^{*} \mathrm{~mm}^{2}\right)$.

Commercially available active pure recombinant human MMP-2 and MMP-9 (Calbiochem, Merck, Millipore, Germany) were loaded into the same gel as positive standard controls.

\section{Inhibition assays:}

Zymograms of both healthy subjects and breast tumor patient's sera were incubated in incubation buffer, added with chemical inhibitors of MMPs (EDTA $20 \mathrm{mM}$ ). Following incubation, at $37{ }^{\circ} \mathrm{C}$ for 18 hours, gels were stained with Coomassie brilliant blue-R-250.

\section{Statistical analysis:}

Data were statistically analysed using the SPSS statistical software (version 20 for windows). Student's unpaired ' $t$ ' test was used to compare the mean levels of MMP-2 and MMP-9 in control group and breast tumor patients. Analysis of variance (ANOVA) was carried out to test significance of both the markers with clinicopathological parameters through Minitab 16 and SPSS (version-20) statistical software. Values of parameters were expressed as Mean \pm S.D. " $p$ " values less than 0.05 (two-sided) were considered to indicate statistically significant result.

\section{Results:-}

A group of 70 patients with primary breast neoplasia, 45 with malignant breast tumor (age range 28-75 years, mean age 46.9 years) and 25 with benign breast disease (age range 28-76 years, mean age 41.7 years), were selected for the present study. The control group consisted of 50 healthy women (age range 28-85 years, mean age 42.9 years). Among 45 malignant breast tumor patients, majority of the patients i.e. $38(84.4 \%)$ were of invasive ductal carcinoma, histological type. Patients with other histopathology types included $3(6.6 \%)$ patients with ductal carcinoma in situ, 2 (4.4\%) patients with invasive lobular carcinoma, and 1 patient each of mammary carcinoma and mucinous adenocarcinoma, respectively. Out of 25 benign breast disease, $19(76 \%)$ of the cases were of fibroadenomas whereas $6(24 \%)$ of the cases were of atypical hyperplasia. The clinicopathological data of all carcinoma patients were obtained and are listed in Table 1.

\section{Standards for latent and active MMP-2 and MMP-9}


Densitometric analysis of active forms of MMP-2 and MMP-9 from 0 to $20 \mathrm{ng}$ and 0 to $1 \mathrm{ng}$, respectively, revealed a linear correlation of density/ cu.mm area with concentration of density/cu.mm area with concentration of gelatinases.

\section{MMP activity in serum euglobulin fraction}

Sera (euglobulin fraction) from all subjects, both affected and healthy ones, were subjected to gelatin zymography to find out the relative levels of activity attributed to MMP-2 and MMP-9. Gelatin zymography shows a distinct and varied profile of MMPs in different groups. The gelatinolytic pattern of the samples displayed different bands of 200, 116, 92, 83, 72 and $63 \mathrm{kDa}$ as shown in (Fig 1).

\section{Expression of matrix metallo proteinases by substrate level gelatin zymography:}

Gelatin zymography identifies and separates the gelatinases, MMP-2 and MMP-9 in both latent and active forms. Two different form of MMP-9 (Gelatinase B) were detected, i.e. the inactive proform/ latent form and its activated form. Gelatinases of $92 \mathrm{kDa}$ and $83 \mathrm{kDa}$ were corresponding to proMMP-9 (or progelatinase B) and an active form of MMP-9, respectively. Simultaneously, MMP-2 (Gelatinase A) was also detected in its inactivated (72 kDa) and activated form $(63 \mathrm{kDa})$. Moreover, most of the sera of malignant breast tumors display two lytic bands of 200 and $116 \mathrm{kDa}$, respectively, absent in the majority of the control sera assayed.

\section{Comparison of MMP-2 and MMP-9 between control group and malignant breast tumor patients:}

(Fig 1) shows representative zymogram of normal person, benign breast disease and malignant breast tumor patients. Forty microgram of proteins was loaded into each lane. Concentration of both forms of MMP-2 and MMP-9 were calculated as $\mathrm{ng} / 40 \mu \mathrm{g}$ of protein. It can be seen from the figure that sera samples of malignant breast tumor showed stronger gelatinolytic activities of MMP-2 and MMP-9 as compared with sera of benign breast disease and normal breast samples. A significant difference was found in concentration of MMP-2 and MMP-9 between control group, benign breast disease and malignant breast tumor patients.

\section{Quantitative analysis of gelatinolytic activity:}

Following zymography, gels containing samples run in duplicate were quantified using density and volume analysis tool (Quantity One Basic- 4.6.9. software and Bio-Rad Image Lab) of Bio-Rad gel documentation system. We calculated volume of each lytic band and then levels of different MMPs were quantified. The activities of both MMPs showed significant quantitative differences between the groups.

\section{Levels of MMP-9 in different study group}

Table 2 shows the comparison of the mean levels of MMP-9 in control group and in patients with benign breast disease and malignant breast tumor. The mean levels of MMP-9 of malignant breast disease were 1.77 fold and 2.03 fold higher as compared to benign breast disease and healthy controls respectively.

\section{Levels of MMP-2 in different study group}

Table 3 shows the comparison of the mean levels of MMP-2 in control group, in benign breast disease and malignant breast tumor patients. The mean levels of MMP-2 in the patients of malignant breast tumor were 1.41 fold and 1.68 fold higher as compared to benign breast disease and healthy controls respectively.

Statistical analysis of the mean levels of MMP-2 and MMP-9 in healthy controls, benign breast disease and malignant breast tumor patients was done by performing student's unpaired ' $\mathrm{t}$ ' test. Statistically significant difference $(p=0.003)$ in levels of MMP-2 were found between patients of benign breast disease and healthy controls as well as in between patients of malignant breast tumor and healthy controls $(p<0.05)$. The mean levels of MMP-9 in the malignant breast tumor were also significantly higher as compared to benign breast disease $(p=0.032)$ and healthy controls $(p<0.05)$.

\section{Correlation between MMP-2 and MMP-9 levels with clinicopathological parameters of malignant breast} tumor:

Statistical analysis was performed using SPSS (version 20) and Minitab 16 statistical software (one way ANOVA test) to evaluate the possible correlation of MMP-2 and MMP-9 levels and the clinicopathological parameters of malignant breast tumor patients (Table 4). The statistical analysis revealed a significant direct correlation between tumor grade and levels of MMP-2 and MMP-9. On the basis of the concentration of MMP-2 and MMP-9, the severity of the diseases can be judged. It indicates that a less differentiated breast cancer should be characterized by 
higher level of MMP-2 and MMP-9. Further, the alterations in MMP-2 and MMP-9 levels were significantly associated with early and advanced stages of the disease in patients of malignant breast tumor. Statistical analysis shows positive correlation between MMP-2 \& MMP-9 level and tumor size. A significant correlation was also observed for MMP-2 and MMP-9 in malignant breast tumor and lymph node involvement. The activity of MMP-2 and MMP-9 in the sera of malignant breast tumor patients did not correlate with age, menopausal status, status of estrogen and progesterone receptors and Her $2 /$ neu.

\section{Identification of gelatinolytic activities:}

The nature of lytic bands observed in zymograms was further confirmed by inhibition assay as shown in Figure 2. Selective inhibitors of MMPs excluded the presence of gelatinolytic activities due to cysteine or serine proteinases. Incubation of the zymograms with $20 \mathrm{mM}$ EDTA inhibited all the gelatinolytic activities of serum samples from both patients and control group. This inhibition indicated the metalloproteinase nature of these gelatinase bands.

\section{Discussion:-}

Breast cancer is the most frequent malignant disease amongst the women of the western world and it is the major cause of death in age group of 40-49 years ${ }^{12,13}$. Collectively, US, India and China account for almost one third of the global breast cancer burden. The breast cancer burden in India has almost reached about 2/3rd of that of the US and is steadily rising.

Current screening methods including mammography, self breast examination and clinical breast examination do not provide sufficient early diagnosis in all patients.Biopsies are too expensive, inaccurate; often leading to misdiagnosis and unnecessary treatments. Therefore, it is very important to search for new molecular markers that should complement to existing screening methods, correlate well with the disease and must be easily monitored, for example by performing a simple blood test. So far no single biomarker with these qualities has been found till date ${ }^{14}$.

In particular, the MMPs have attracted the interest of researchers due to their possible use as molecular markers and therapeutic targets ${ }^{15}$. MMPs can occur in different forms and secreted in body fluids where they can get easily detected. Various types of assays such as ELISA (Enzyme Linked Immunosorbent Assay), Immunohistochemistry and Zymography are used to detect MMPs. Most of the studies have focused on measuring MMPs by ELISA, which use specific polyclonal and monoclonal antibodies, but is very costly on routine basis; while, Immunochemistry cannot distinguish between latent and active forms of MMPs.

The current study assesses the levels of MMP-2 and MMP-9 in normal person, patients of benign breast disease and malignant breast tumor by zymography. Firstly, we developed zymograms of both the forms of MMP-2 and MMP-9 standards, which showed a linear correlation with concentrations against gelatinolytic activity in terms of optical density per cu.mm area. Similar zymograms of standards were also developed by Patel et al. ${ }^{16}$ using zymography. Further, total of four different forms of MMP-2 and MMP-9 with molecular masses of $92 \mathrm{kDa}$ (ProMMP-9), $83 \mathrm{kDa}$ (Active MMP-9), $72 \mathrm{kDa}$ (ProMMP-2) and $63 \mathrm{kDa}$ (Active MMP-2) were detected in the patients of malignant breast tumor by performing gelatin zymography. In addition, two other lytic bands of larger molecular size were observed in the sera samples from malignant breast tumor, similar to those previously identified as proMMP-9 dimers $(200 \mathrm{kDa})$ and as a complex formed between proMMP-9 and its physiological inhibitor TIMP-1 (116kDa) in colon cancer sera ${ }^{17}$. These forms were very faint or totally absent in the majority of normal sera.

Our quantitative analysis showed that the levels of MMP-2 were significantly higher in malignant breast tumor patients as compared to benign breast disease and control group. MMP-9 levels were also significantly higher in malignant breast tumor patients as compared to benign breast disease patients and normal persons. In accordance with the results of the current study, Shah et al. ${ }^{18}$ found that active MMP-2 and MMP-9 levels were 2.6 folds and 1.3 folds higher, respectively, in malignant breast tumour as compared to normal patients. Liu et al. ${ }^{19}$ also reported significantly higher levels of pro and active MMP-2 and MMP-9 in tumor tissues than in the corresponding paired adjacent normal tissues. Various studies, by gelatin zymography, showed that active MMP-2 and active MMP-9 levels were higher in malignant breast cancer as compared to their normal counterparts $\mathrm{s}^{20,21}$.

It is observed that benign cancer cells acquire malignant properties when MMP expression is upregulated. Conversely, highly malignant cells become less aggressive when MMP expression or activity is reduced. It is already well known that MMPs play role in several steps of cancer local invasion and metastasis. Increased proteolysis in tumor tissues plays a critical role in these events thus, increased proteolytic enzyme activity is often 
found in tumor tissues ${ }^{22}$. Both MMPs and TIMPs have an important role in remodeling the extracellular matrix components of the basement membrane that facilitate cancer cell invasion and metastasis ${ }^{23}$. In particular, MMP-2 has been studied for its involvement in breast cancer progression, and the positive immunostaining of the enzyme has been proposed to be a marker of aggressiveness in breast carcinoma. However, it has been demonstrated that blocking MMP-2 secretion and activation may reduce the risk of breast cancer metastasis ${ }^{24}$. As the concentration of specific MMPs is increased in the serum of tumoral patients, including breast neoplasia, the combined determination of MMP-2, MMP-9 and TIMP-1 has been proposed as a significant tumor marker in blood plasma for bladder cancer diagnosis ${ }^{25}$. Our data shows that, sera MMP-2 level was significantly higher in malignant breast tumor patients than in normal healthy person. This result agrees with those of a previous study, which reported that the blood levels of MMP-2 were higher in breast cancer patients than in healthy blood donors ${ }^{26}$. Furthermore, an elevated activity of pro MMP-2 and pro MMP-9 has been described in the serum of mammary neoplasia patients and has been correlated with tumor size and lymph node status, indicates these enzymes can be utilized as staging markers for breast cancer ${ }^{27,28}$.

We next determined whether the levels of serum activity levels of MMP-2 and MMP-9 is associated with current clinicopathological parameters in breast cancer patients. We applied statistical analysis to correlate activity levels of both enzymes with clinical parameters in malignant breast lesions patients. The significant association was found between MMP-2 and MMP-9 with breast tumor stage and T factor. The alterations in MMP-2 and MMP-9 levels were significantly associated with the early and advance stages of the disease in breast tumor patients. We also found that high levels of MMP-2 and MMP-9 were significantly associated with lymph node metastasis. These results are similar with the findings of Zheng-Sheng et al. ${ }^{9}$, which also suggest that high levels of MMP-9 and TIMP-I proteins were significantly associated lymph node metastasis. Further data were obtained with regard to the correlation of MMP-2 and MMP-9 concentrations with the G value of the tumor which also showed significant associations. Susana et al. ${ }^{29}$ have also reported that increased concentrations of MMP-2 and MMP-9 were correlated significantly with the histological grade of the tumor, meaning that a less differentiated breast cancer should be characterized by higher levels of MMPs 2 and 9 . However, we have not observed significant changes of MMP- 2 and MMP-9 activities between different clinicopathological finding including age, menopausal status, status of estrogen and progesterone receptors and Her2/neu.

From our analysis we found zymography as a very simple, sensitive and functional assay which can separate and quantify latent as well as active forms of MMP-2 and MMP-9. Separation of MMPs in different forms is the most advantageous feature of this technique. Hence, easy reproducibility and cost-effectiveness of gelatin zymography make it possible for routine analysis for each patient. Therefore, it is our strongest recommendation that detection of these molecular markers, i.e. MMP-2 and MMP-9 should be added (as molecular diagnostic test) first in the cancer institute and then all cancer hospitals for the diagnosis of cancer.

To the best of our knowledge, ours is the first Indian study in which activated form and the latent proenzyme of gelatinases (MMP-2 and MMP-9) was resolved by using gelatin zymography in benign breast disease as well as in malignant breast cancer patients. In conclusion, the results of present study on the detection of MMP-2 and MMP-9 approve the significance of these proteolytic enzymes in tumor invasion and metastasis in breast cancer. It can be also concluded that simultaneous analysis of these gelatinases by gelatin zymography apart from cytology and histopathology could clinically be useful for diagnosis of early as well as advance stages of breast cancer. Therefore, our findings suggest the importance of the detection of serum MMP-2 and MMP-9 as additional biomarkers for the diagnosis of breast cancer and it could be an important contribution in developing a new targeted therapy for breast cancer. The full potentials of these markers may need to be determined using a larger sample size study prior to a detailed prospective clinical assessment.

\section{Conflict Of Interest}

The author declares that no competing interests exist.

\section{Acknowledgements:-}

The author acknowledges guidance received from Dr. Prabhudas Patel, Professor and Head, Cancer Biology Department, The Gujarat Cancer and Research Institute, Ahmedabad, Gujarat, India and Dr. Jagdish Patel, ExAssociate Professor, Biochemistry department, P.D.Patel Institute of Applied Science, Changa, Gujarat, India. 
Table 1:-Clinicopathological details of malignant breast tumor patients

\begin{tabular}{|c|c|c|}
\hline Characteristics & $\mathbf{N}$ & $\%$ \\
\hline Total & 70 & \\
\hline $\begin{array}{l}\text { Diagnosis } \\
\text { Malignant breast lesions } \\
\text { Benign breast lesions }\end{array}$ & $\begin{array}{l}45 \\
25\end{array}$ & $\begin{array}{l}64.2 \\
55.5\end{array}$ \\
\hline $\begin{array}{l}\text { Menopausal Status } \\
\text { Premenopausal } \\
\text { Postmenopausal } \\
\text { Perimenopausal }\end{array}$ & $\begin{array}{l}23 \\
17 \\
05\end{array}$ & $\begin{array}{l}51.1 \\
37.7 \\
11.1\end{array}$ \\
\hline $\begin{array}{l}\text { Stages } \\
\text { Stage I } \\
\text { Stage II } \\
\text { Early disease (Stage I+ Stage II) } \\
\text { Stage III } \\
\text { Stage IV } \\
\text { Advance disease (Stage III + Stage IV) }\end{array}$ & $\begin{array}{l}04 \\
21 \\
25 \\
19 \\
01 \\
20 \\
\end{array}$ & $\begin{array}{l}8.80 \\
46.6 \\
55.6 \\
42.2 \\
2.2 \\
44.4 \\
\end{array}$ \\
\hline $\begin{array}{l}\text { T Factor } \\
\text { T1 } \\
\text { T2 } \\
\text { T3 } \\
\text { T4 }\end{array}$ & $\begin{array}{l}04 \\
21 \\
11 \\
09\end{array}$ & $\begin{array}{l}8.8 \\
46.6 \\
24.4 \\
20\end{array}$ \\
\hline $\begin{array}{l}\text { N Factor } \\
\mathrm{N}-\text { (Negative) } \\
\mathrm{N}+\text { (Positive) }\end{array}$ & $\begin{array}{l}17 \\
28\end{array}$ & $\begin{array}{l}37.7 \\
62.2\end{array}$ \\
\hline $\begin{array}{l}\text { Grading } \\
\text { G1 } \\
\text { G2 } \\
\text { G3 }\end{array}$ & $\begin{array}{l}09 \\
16 \\
20\end{array}$ & $\begin{array}{l}20 \\
35.5 \\
44.4\end{array}$ \\
\hline
\end{tabular}

\begin{tabular}{|l|l|l|}
\hline Estrogen Receptor (ER) & 28 & 62.2 \\
Negative & 17 & 37.7 \\
Positive & & 64.4 \\
\hline Progesterone Receptor (PR) & 29 & 35.5 \\
Negative & 16 & 68.8 \\
Positive & 31 & 31.1 \\
\hline HER2/ neu & 31 & 14 \\
Negative (Score 0-1) & \\
Positive (Score 2-3) & \\
\hline
\end{tabular}

Table 2:-Levels of MMP-9 in different study group

\begin{tabular}{|l|l|}
\hline Pathology & $\begin{array}{l}\text { Mean MMP.9 activity } \\
\text { (U/40 } \boldsymbol{\mu g} \text { protein } \pm \text { S.D. })\end{array}$ \\
\hline Normal Person (Control Group) & $11.62 \pm 4.82$ \\
\hline Benign Breast Disease & $13.33 \pm 1.90$ \\
\hline Malignant Breast Tumor & $23.64 \pm 7.24$ \\
Grade I & $13.97 \pm 2.52$ \\
Grade II & $19.17 \pm 2.20$ \\
Grade III & $29.47 \pm 5.20$ \\
Grade VI & 38.3 \\
\hline
\end{tabular}

Table 3:-Levels of MMP-2 in different study group

\begin{tabular}{|l|l|}
\hline Pathology & $\begin{array}{l}\text { Mean MMP-2 activity } \\
\text { (U/40 } \boldsymbol{\mu g} \text { protein } \pm \text { S.D.) }\end{array}$ \\
\hline Normal Person (Control Group) & $8.5 \pm 1.48$ \\
\hline
\end{tabular}




\begin{tabular}{|l|l|}
\hline Benign Breast Disease & $10.1 \pm 2.2$ \\
\hline Malignant Breast Disease & $14.29 \pm 4.07$ \\
Grade I & $8.2 \pm 0.34$ \\
Grade II & $12.09 \pm 2.31$ \\
Grade III & $17.37 \pm 1.49$ \\
Grade VI & 26.6 \\
\hline
\end{tabular}

Table 4:-Correlation analysis between MMP-2 and MMP-9 detection and clinicopathological parameters in patients of malignant breast tumor

\begin{tabular}{|c|c|c|c|}
\hline Characteristics & $\mathbf{N}$ & MMP-2 & MMP-9 \\
\hline $\begin{array}{l}\text { Age (years) } \\
<35 \\
35-45 \\
46-55 \\
>55\end{array}$ & $\begin{array}{l}07 \\
15 \\
13 \\
10\end{array}$ & $\begin{array}{l}\mathrm{F}=0.604 \\
p=0.616\end{array}$ & $\begin{array}{l}\mathrm{F}=0.306 \\
p=0.821\end{array}$ \\
\hline $\begin{array}{l}\text { Menopausal Status } \\
\text { Premenopausal } \\
\text { Postmenopausal } \\
\text { Perimenopausal }\end{array}$ & $\begin{array}{l}23 \\
17 \\
05\end{array}$ & $\begin{array}{l}\mathrm{F}=0.709 \\
p=0.460\end{array}$ & $\begin{array}{l}\mathrm{F}=0.170 \\
p=0.844\end{array}$ \\
\hline $\begin{array}{l}\text { Stages } \\
\text { Stage I } \\
\text { Stage II } \\
\text { Stage III } \\
\text { Stage IV } \\
\text { Early disease (Stage I+ Stage II) } \\
\text { Advance disease (Stage III + Stage IV) }\end{array}$ & $\begin{array}{l}04 \\
21 \\
19 \\
01 \\
25 \\
20\end{array}$ & $\begin{array}{l}\mathrm{F}=27.77 \\
p=0.000 \\
p=0.000\end{array}$ & $\begin{array}{l}\mathrm{F}=27.85 \\
p=0.000 \\
p=0.460\end{array}$ \\
\hline $\begin{array}{l}\text { T Factor (Tumor Size) } \\
\text { T1 } \\
\text { T2 } \\
\text { T3 } \\
\text { T4 }\end{array}$ & $\begin{array}{l}04 \\
21 \\
11 \\
09\end{array}$ & $\begin{array}{l}\mathrm{F}=19.62 \\
p=0.000\end{array}$ & $\begin{array}{l}\mathrm{F}=15.85 \\
p=0.000\end{array}$ \\
\hline $\begin{array}{l}\text { Lymph node involvement (N Factor) } \\
\mathrm{N}-\text { (Negative) } \\
\mathrm{N}+\text { (Positive) }\end{array}$ & $\begin{array}{l}17 \\
28 \\
\end{array}$ & $p=0.005$ & $p=0.001$ \\
\hline $\begin{array}{l}\text { Grade } \\
\text { I (G1) } \\
\text { II (G2) } \\
\text { III (G3) }\end{array}$ & $\begin{array}{l}09 \\
16 \\
20\end{array}$ & $\begin{array}{l}\mathrm{F}=5.80 \\
p=0.006\end{array}$ & $\begin{array}{l}\mathrm{F}=4.35 \\
p=0.019\end{array}$ \\
\hline $\begin{array}{l}\text { Estrogen receptor (ER) } \\
\text { Negative }(-) \\
\text { Positive }(+)\end{array}$ & $\begin{array}{l}28 \\
17 \\
\end{array}$ & $p=0.198$ & $p=0.107$ \\
\hline $\begin{array}{l}\text { Progesterone receptor (PR) } \\
\text { Negative }(-) \\
\text { Positive }(+)\end{array}$ & $\begin{array}{l}29 \\
16 \\
\end{array}$ & $p=0.375$ & $p=0.240$ \\
\hline $\begin{array}{l}\text { HER 2/ neu } \\
\text { Negative (-) } \\
\text { Positive (+) }\end{array}$ & $\begin{array}{l}31 \\
14 \\
\end{array}$ & $p=0.002$ & $p=0.008$ \\
\hline
\end{tabular}




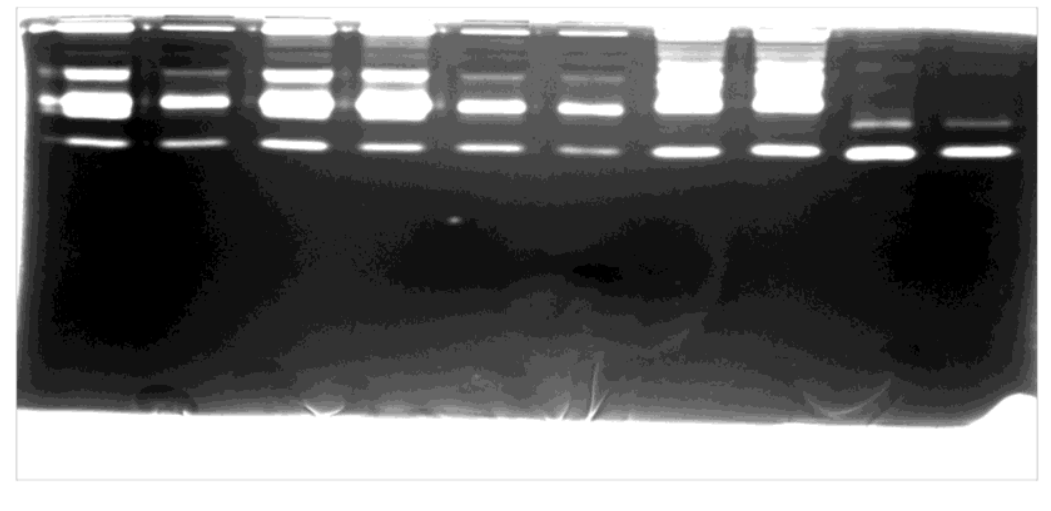

igure 1: Representative gelatin zymogram of normal person, benign breast lesion and talignant breast lesion with standards. Lanes 1 and 2 represent MMP-2 and MMP-9 andards respectively. Lanes 3 and 4 represent the malignant breast lesion (stage-IV). ane 5 represents the normal person. Lanes 6 and 9 represent benign breast lesion. Lanes 8,10 represent the malignant breast lesions (stage-I, stage-II, stage-III)

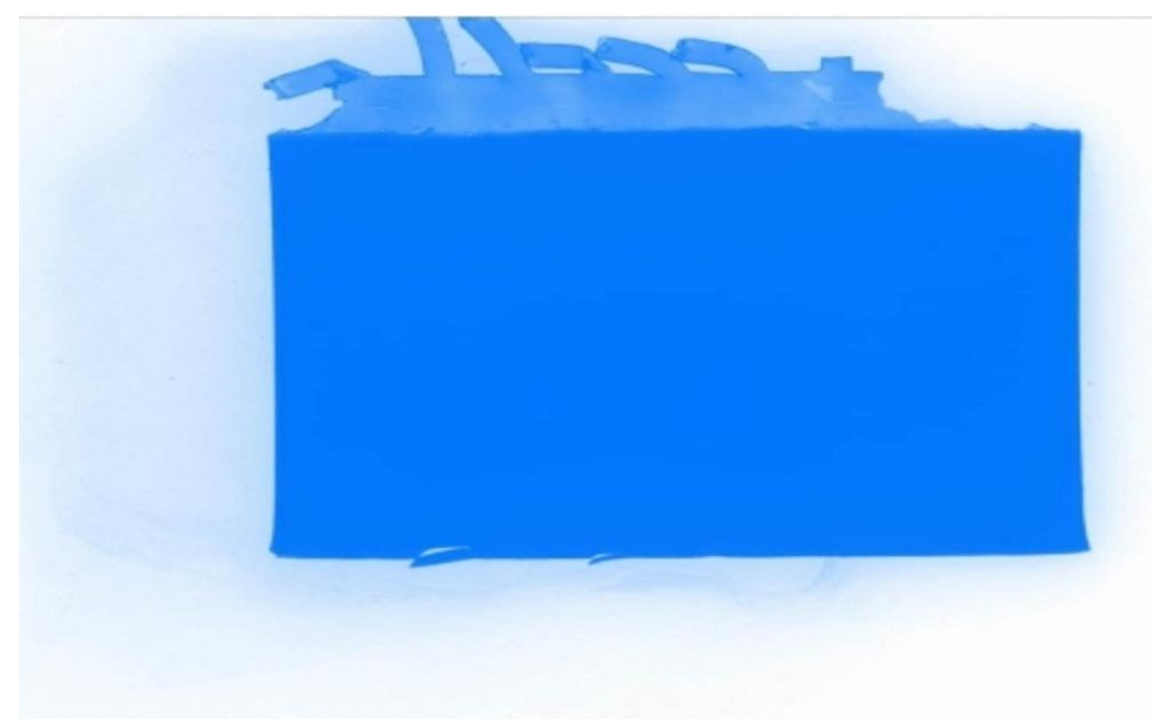

Fig 2:-Inhibition Assay- Gels containing breast cancer samples were incubated in the presence of $20 \mathrm{mM}$ EDTA inhibited MMPs activities

\section{References:-}

1. Agarwal, G., Ramakant, P. and Forgach, ER. (2009): Breast cancer care in developing countries. World J Surg., 33:2069-76.

2. Dikshit, R., Gupta, PC.,Ramasundarahettige, C., Gajalakshmi, V., Aleksandrowicz, L., Badwe, R., et al. (2012): Cancer mortality in India: A nationally representative survey. Lancet., 379:1807-16.

3. Crowe, DL., Tsang, KJ., Shemirani, B. (2001): Jun N-terminal kinase 1 mediates transcriptional induction of matrix metalloproteinase 9 expression. Neoplasia., 3:27-32.

4. Hanahan, D. and Weinberg RA. (2000): The hallmarks of cancer. Cell.,100: 57-70.

5. Nagase, H., Visse, R., Murphy, G. (2006): Structure and function of matrix metalloproteinases and TIMPs. Cardiovasc Res., 69 (3): 562-73.

6. Garbett, EA., Reed, MWR., Stephenson, TJ., Brown, NJ.(2000): Proteolysis in human breast cancer. J ClinPathol, MolPatho.,53:99-106.

7. Sternlicht, MD., Coussens, LM., Vu, TH., Werb, Z. (2001): Biology and regulation of the matrix metalloproteinases. In: Appelt K, ed. Matrix metalloproteinase inhibitors in cancer therapy. Totowa, NJ: Humana 1-37. 
8. Nagase, H. (2001): Substrate specificity of MMPs. In: Appelt K, ed. Matrixmetalloproteinase inhibitors in cancer therapy. Totowa, NJ: Humana 39-66.

9. Zheng-Sheng,Wu., Qiang, Wu., Jiu-Hua, Yang., Hong-Qun, Wang., Xiang-Dong, Ding., Feng, Yang. and XiaoChun, Xu. (2008): Prognostic significance of MMP-9 and TIMP-1 serum and tissue expression in breast cancer. Int. J. Cancer., 122: 2050-2056.

10. Hanemaaijer, R., Verheijen, JH., Maguire, TM., Visser, H., Toet, K., McDermott, E., O’Higgins, N., Duffy, MJ. (2000): Increased gelatinase-A and gelatinase-B activities in malignant vs. benign breast tumors. Int J Cancer., 86:204-7.

11. Ranuncolo, SM., Armanasco, E., Cresta, C., Joffe, EB., and Puricelli, L. (2003): PlasmaMMP-9 (92-kDAMMP) activity is useful in the follow-up and in the assessment of prognosis in breast cancer patients. Int $\mathrm{J}$ Cancer., 106:745-51.

12. Jemal, A., Murray, T., Ward, E., Samuels, A., Tiwari, RC.,Ghafoor, A., Feuer, EJ., Thun, MJ. (2005): Cancer statistics 2005. CA Cancer J Clin., 55:10-30.

13. Duffy, M.J. (2001): Biochemical markers in breast cancer: which ones are clinically useful? ClinBiochem., 34 : 347-52.

14. Arciero, C., Somiari, S., Shriver, C. (2003): Functional relationship and gene ontology classification of breast cancer biomarkers. Int J Biol Markers., 18: 241-72.

15. King, J., Zhao, J., Clingan, P., Morris, D. (2003): Randomised double blind placebo control study of adjuvant treatment with the metalloproteinase inhibitor, Marimastat in patients with inoperable colorectal hepatic metastases: significant survival advantage in patients with musculoskeletal side-effects. Anticancer Res., 23: 639-645.

16. Patel, B.P., Shah, S.V., Shukla, S.N., Shah, P.M. and Patel, P.S. (2007): Clinical significance of MMP-2 and MMP-9 in patients with oral cancer. Wiley Inter Science., 29:564-572.

17. Pucci-Minafra, I., Minafra, S., La Rocca, G., Barranca, M., Fontana, S. and Alaimo, G. (2001): Zymographic analysis of circulating and tissue forms of colon carcinoma gelatinase A (MMP-2) and B (MMP-9) separated by mono- and two-dimensional electrophoresis. Matrix Biol., 20:419-27.

18. Shah, F.D., Shukla, S.N., Shah, P.M., Shukla, H.K. and Patel, P.S. (2009): Clinical significance of matrix metalloproteinase 2 and 9 in breast cancer. Indian Journal of Cancer., 46 (3): 194-202.

19. Liu, S.C., Yang, S.F., Yeh, K.T., Yeh, C.M., Chiou, H.L. and Lee C.Y. (2006): Relationship between the level of matrix metalloproteinase-2 and tumor size of breast cancer. ClinChimActa., 371: 92-6.

20. Schutz, A., Schneidenbach, D., Aust, G., Tannapfel, A., Steinert, M. and Wittekind, C. (2002): Differential expression and activity status of MMP-1, MMP-2 and MMP-9 in tumor and stromal cells of squamous cells carcinoma of the lung. Tumor Biol., 23: 179-84.

21. Hong, S.D., Hong, S.P., Lee, J.I. and Lim C.Y. (2005): Expression of matrix metalloproteinase-2 and -9 in oral squamous cell carcinoma with regard to the metastatic potential. Oral Oncol., 90: 81-8.

22. Rocca, G.L., Pucci-Minafra, I., Marrazzo, A., Taormina, P. and Minafra, S. (2004): Zymographic detection and clinical correlations of MMP-2 and MMP-9 in breast cancer sera. British journal of cancer., 90: 1414-1421.

23. Garbett, E.A., Reed, M.W., Stephenson, T.J. and Brown, N.J. (2000): Proteolysis in human breast cancer. MolPathol., 53: 99-106.

24. Jezierska, A. and Motyl, T. (2009): Matrix metalloproteinase-2 involvement in breast cancer progression: a mini-review. Med SciMonit., 15: RA32-RA40.

25. Staack, A., Badendieck, S., Schnorr, D., Loening, S.A. and Jung, K. (2006): Combined determination of plasma MMP2, MMP9, and TIMP1 improves the non-invasive detection of transitional cell carcinoma of the bladder. BMC Urol., 6: 19.

26. Incorvaia, L., Badalamenti, G., Rini, G., Arcara, C., Fricano, S., Sferrazza, C., Di Trapani, D., Gebbia, N. and Leto, G. (2007): MMP-2, MMP-9 and activinA blood levels in patients with breast cancer or prostate cancer metastasis to the bone. Anticancer Res., 27: 1519-1525.

27. Jinga, D.C., Blidaru, A., Condrea, I., Ardeleanu, C., Dragomir, C., Szegli, G., Stefanescu, M. and Matache, C. (2006): MMP-9 and MMP-2 gelatinases and TIMP-1 and TIMP-2 inhibitors in breast cancer: correlations with prognostic factors. J Cell Mol Med 2006., 10: 499-510.

28. Stankovic, C., Konjevic, G., Gopcevic, K., Jovic, V., Inic, M. and Jurisic, V. (2010): Activity of MMP-2 and MMP-9 in sera of breast cancer patients. Pathol Res Pract., 206: 241-247.

29. Fortunata, V., Fabiana, S., Carolina, M., Tiziana, N., Bruno, V., Mauro, M. and Susanna S. (2013): Plasma levels of matrix metalloproteinases 2 and 9 correlate with histological grade in breast cancer patients. Oncology Letters., 5: 316-320. 